\begin{tabular}{|l|ccc|}
\hline \multicolumn{4}{|c|}{ PORT SAID ENGINEERING RESEARCH JOURNAL } \\
\hline \multirow{3}{*}{ Volume 22} & Faculty of Engineering - Port Said University & pp: $46: 55$ \\
\hline
\end{tabular}

\title{
Ultimate Strength behavior of Aluminum Stiffened Panel under Combined Load
}

\author{
S.A. El-Tawosy ${ }^{\text {, R. Ramadan }}{ }^{2}$, M. Mansour ${ }^{3}$ and H.S. El-Kilani ${ }^{4}$
}

\begin{abstract}
Aluminum has become the material of choice for many types of vessels, particularly high-speed vessels where lightweight structure is important for meeting design goals. The methods of design and fabrication of aluminum contain many areas of conservatism that if overcome by proper research will lead to even greater performance at reduced cost. This paper studies the ultimate strength of Aluminum stiffened panel under combined loading conditions. A Finite Element Model had been developed based on published experimental study, this model was validated by comparing the output results with experimental work. The model calculated the ultimate strength of the panel under axial load. After validation of the model, it is used to estimate the ultimate strength of the aluminum stiffened panel under combined load. It is intended to investigate the effect of initial imperfection on the ultimate strength of the aluminum panels into the finite-element models studied. The effect of change in panel aspect ratio and the effect of column slenderness ratio are investigated. It has been found that an increase in aspect ratio affects the ability of the panel withstand any increase in load especially in case of imperfections. The analysis for the forcedisplacement relationships and post-collapse deformed shapes is also investigated.
\end{abstract}

Key Words: Aluminum stiffened panel, Ultimate strength, Aluminum in ship structure, Combined load, Buckling, Imperfections, Aspect ratio, Slenderness ratio.

\section{INTRODUCTION}

From 1891 to 1897 , many attempts were made both in the United States and Europe to build aluminium ships. In spite of short-lived, these experiments were illuminating and informative, and the performance of these vessels revealed the full potential of aluminium for marine applications [1].

In the Nineteen Thirties, aluminium's adventure in ship construction was reintroduce on new concepts based on the usage of specific alloys and assembly methods that have continued to develop to the present day. Although much more expensive than steel, some 30 times more in 1895 , aluminium quickly aroused the maritime circles interest. Its lightness was initially the main reason for usage of in shipbuilding [2]. The very first aluminum boat known was a "steam launch" 5.50 metres length, with a 1.28 metres beam and a 0.61 metres draft, was built by the Swiss shipyard Escher Wyss in Zurich in 1891. Its hull alone weighed 440 $\mathrm{kg}$. This boat was powered by a steam engine that ran on oil [3]. Swiss shipyard Escher Wyss in Zurich. Its hull alone weighed $440 \mathrm{~kg}$.

${ }^{I}$ Demonstrator, Naval Architecture and Marine Engineering, Department, Faculty of Engineering, Port Said University, Port Said, Egypt, E-mail: sara.ali987@ gmail.com

${ }^{2}$ Lecturer, Naval Architecture and Marine Engineering Department, Faculty of Engineering, Port Said University, Port Said, Egypt,

E-mail: randa5r@gmail.com

${ }^{3}$ Emeritus Professor, Naval Architecture and Marine Engineering Department, Faculty of Engineering, Port Said University, Port Said, Egypt, E-mail: sohimo@hotmail.com

${ }^{4}$ Professor, Naval Architecture and Marine Engineering Department, Faculty of Engineering, Port Said University, Port Said, Egypt, E-mail: hebaelkilani@eng.psu.edu.eg.
This boat was powered by a steam engine that ran on oil [3].

Boat and high speed catamaran builders, for the first time during 1990's, implemented Aluminum panels for marine applications (Collette). The main role of these panels is strengthening against in-plane compression. It is not accepted to extend the formulations for of steel panels strength to the aluminum panels since to have different stress-strain relationship than that of structural steel. In the elastic-plastic range after the proportional limit as compared to structural steel, the strain hardening has a significant influence in the ultimate load behavior of aluminum structures whereas in steel structures, the elastic-perfectly plastic material model is well adopted [4].

Studying the ultimate strength of aluminum was performed by many authors. Wang el al., 2005 developed a criterion for buckling and ultimate strength of plate and stiffened panels subjected to longitudinal compression, and validate the criteria by non-linear Finite Element Method.

The authors investigated typical "marine" grade aluminum alloys. Buckling and ultimate strength formulas for plate panels and stiffened panels in aluminum ship structures were proposed. Based on the previous experiences from steel structures, a modified Faulkner's formula was put forward for ultimate strength of plate under longitudinal compression and a reduction factor is introduced to take into account the heat affected zone HZA softening effect.

Closed-form empirical ULS formulas for aluminum stiffened plate structures were developed by the regression analysis of experimental and numerical Ultimate strength database obtained from the present study [5]. 
Paik et al., 2007, performed a buckling collapse testing on 78 prototype structures. The load-axial displacement curves were obtained until and after the ultimate strength are reached. Nonlinear elastic-plastic large deflection finite element analyses were performed for the prototype structures. The ultimate strength characteristics of the structures together with collapse modes were investigated in terms of plate slenderness ratio and column slenderness ratio as well as initial imperfectios. Closed-form empirical ULS formulas for aluminum stiffened plate structures were developed by the regression analysis of experimental and numerical Ultimate strength database obtained from the present study [6].

Khedmati et al., 2009, developed empirical expressions are for predicting ultimate compressive strength of welded stiffened aluminum plates used in marine applications under combined in-plane axial compression and different levels of Lateral pressure. The formulations that were expressed as functions of two parameters; the plate slenderness ratio and the column slenderness ratio. The empirical formula was made by regression analysis. The formulae implicitly included effects of the weld on initial imperfections, and the heat-affected zone [7].

Pedram and Khedmati, 2012, studied the response of stiffened aluminum panels under the action of combined inplane compression and lateral pressure considering both geometrical and mechanical imperfections. Based on extensive finite-element investigations different aspects of the effect of welded induced initial imperfections on aluminium panels were outlined and some design-oriented conclusions were made [8].

Teresa Magoga et al., 2013, investigated the use of the state-of-the-art rapid assessment procedure ISFEM (intelligent supersize finite element method) to examine the ultimate hull-girder strength under vertical and horizontal bending of a metal inert gas welded aluminium midship section with plate and stiffener scantlings typical of a highspeed patrol vessel. The analysis investigates the effect on ultimate strength of weld-induced imperfections including plate and stiffener distortion, residual stresses and material softening in the weld heat-affected zone [9].

Mohammad Khedmati et al., 2015, generated a numerical database of the ultimate strengths for stiffened aluminium plates. And then he applied regression analysis to derive the empirical formulations as functions of two parameters, to be exact the plate slenderness ratio and the column slenderness ratio. The formulae indirectly include the effects of initial imperfections and heat affected zone[10].

Chenfeng Li et al., 2018, used a finite element code to reproduce the mechanical response of the stiffened panels under the axial compression. The fabrication related imperfections, like initial deformations, residual stresses and softening of material in Heat-Affected Zone (HAZ) are simulated. The experimental response curves are compared with the numerical simulations, and sensitivity to geometric parameters, material properties and initial imperfections are analysed. The results show that for the considered panel: 1)
The ultimate strength is more sensitive to the cross-section dimensions than to the length.2) The initial deformation has a strong effect on both the level of ultimate strength and the failure mode. 3) Both the width of the HAZ and the yield strength in the HAZ has little effect on the ultimate strength of the considered aluminium integrally stiffened panels. 4) The residual stresses will improve the ultimate strength for the considered panels [11].

The aim behind this paper is to study the behavior of a stiffened alumium panel when subjected to axial and lateral load. Finite Element Model was built for a stiffened panel. The load was inputted incrementally until the ultimate strength is reached. The ultimate strength was also investigated with and without imperfections.

\section{FINITE ELEMENT MODEL}

In this paper ultimate strength of an aluminum panel is studied using Finite Element Analysis. One of Paik et al., (2007)'s models is selected for the study to compare FEA with expermental work of the authors [6].

\subsection{Description the Model}

Numerical analyses of the ultimate strength for plate is performed based on general nonlinear finite element commercial code- ANSYS. The plate is modelled in an equivalent manner as the one used during the ultimate strength test done by Paik [2007]. without any simplifications. The finite element analysis uses the full Newton- Raphson equilibrium iteration scheme. The large deformation option was activated to solve the geometric and material nonlinearities and to pass through the extreme points. The automatic time stepping features are employed allowing the program to determine appropriate load steps. Figure 1: shows the geometry of the panel and dimensions is presented in table 1, and the material of the model: the panel of the plate is made from 5083 -H116 aluminum alloy, stiffeners are made from 5383- H112 aluminum alloy.

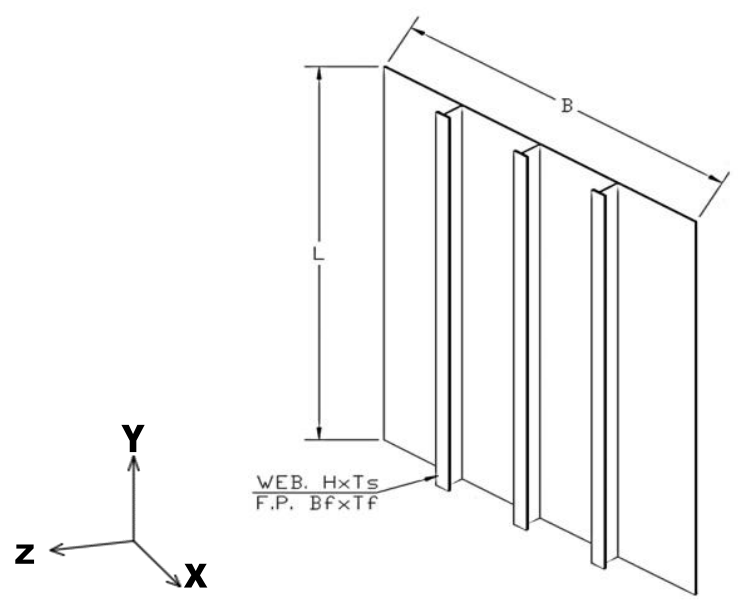

Fig 1: Model Geometry

Table 1: Principal Characteristics of the Model 


\begin{tabular}{|c|c|c|}
\hline Items & Dimensions & Units \\
\hline Plate Length & 1200 & $\mathrm{~mm}$ \\
\hline Plate Breadth $\mathrm{B}$ & 1000 & $\mathrm{~mm}$ \\
\hline Plate Thickness $\mathrm{t}$ & 5 & $\mathrm{~mm}$ \\
\hline Flange breadth $\quad B_{f}$ & 40 & $\mathrm{~mm}$ \\
\hline Flange thickness $T_{f}$ & 6.7 & $\mathrm{~mm}$ \\
\hline Web height & 55.7 & $\mathrm{~mm}$ \\
\hline Web thickness $T_{s}$ & 3.7 & $\mathrm{~mm}$ \\
\hline
\end{tabular}

\subsection{Finite Element Code and Adopted Elements}

The commercial finite element code ANSYS [9] is used for all analyses. Among the elements inside the library of ANSYS, SHELL 181 element was used to generate the entire FE model. SHELL 181 is defined by four-nodded element with six degrees of freedom at each node: translations in the $\mathrm{x}, \mathrm{y}$ and $\mathrm{z}$ directions, and rotations about the $\mathrm{x}, \mathrm{y}$ and $\mathrm{z}$ axes. SHELL181 is well-suited for linear, large rotation, and/or large strain nonlinear applications and suitable for analysing thin to moderately-thick shell structures.

\subsection{Boundary Conditions}

One of the most serious tasks related to the proper modelling of ship structures using finite elements is the definition of the boundary conditions. Incorrect boundary conditions may introduce considerable errors by suppressing the deformation of the cross sections at which they are applied or by giving rise to deformation modes that are not realistic.

The boundary conditions were chosen to accurately simulate the behaviour of the aluminum stiffened panel under axial load.

-Two sides

The two sides are simply supported

-Displacement in longitudinal direction $\mathrm{u}_{\mathrm{x}}=0$

-Displacement in normal to the plate $\mathrm{u}_{\mathrm{z}}=0$

-Rotation in transverse direction $\quad \Theta_{\mathrm{x}}=0$

- Lower edge

-Fully fixed, rotation and displacement restrained in all direction.

-Top edge

- Displacement in longitudinal direction $\mathrm{u}_{\mathrm{x}}=0$

- Displacement in normal to the plate $\quad \mathrm{u}_{\mathrm{z}}=0$

- Rotation in longitudinal direction $\quad \Theta y=0$

\subsection{Loading Condition}

The basic load simulating the expermental load and in calibration and validation stages is axial load. The value of the axial load was applied incrementally on the top edge of the plate in $[-\mathrm{Y}]$ direction.

\subsection{Global Initial Imperfections}

To consider the initial deflection of the model, the axial load was applied first on the stiffened plate model and nonlinear elastic finite element analysis was carried out. This analysis was repeated in a trial and error sequence of calculations so that the magnitude of maximum deflection of plate [amplitude] reached $3 \mathrm{~mm}$.

\subsection{Model Validation}

A series of nonlinear FEA has been performed for a plate to analyses the effect of several parameters on the ultimate strength. In order to validate the FE model, a compression between the expermental work results as shown in figure 2 and FE model results as shown in figure 3 was made. The differential percentage of maximum load between the present numerical model and the experimental work is $1.8 \%$.

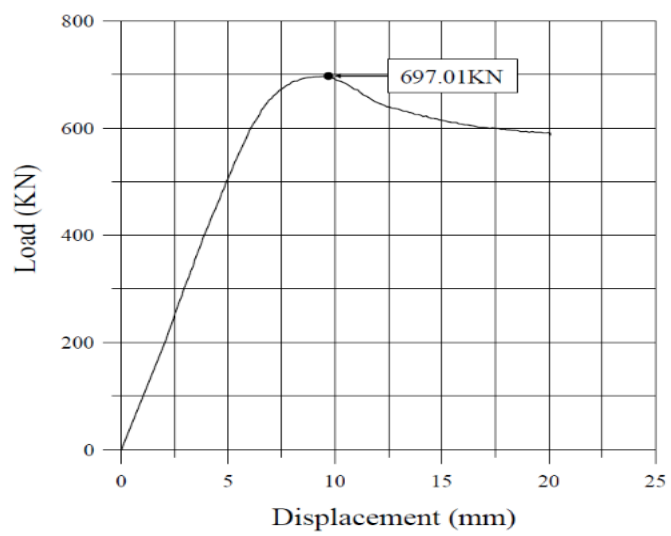

Fig 2: Experimental Work Results

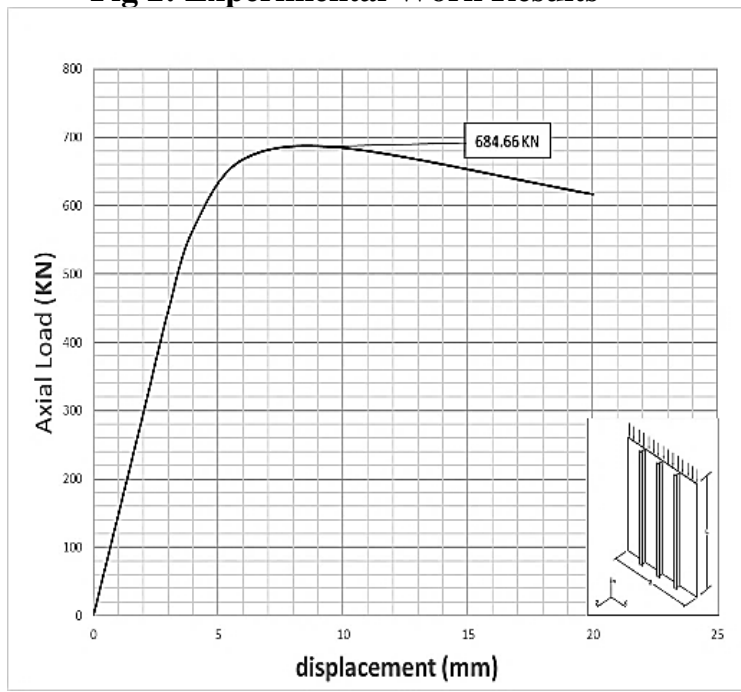

Fig 3: FE Model Results

The panel collapsed by column type collapse (Mode III) as in the experimental work as shown in figure 4. 


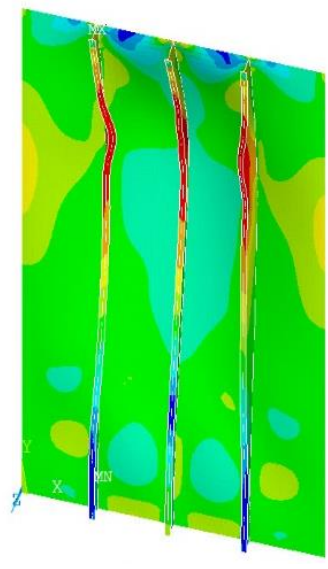

Fig 4: Biaxial (uniaxial) Compressive Collapse

The value of imperfections (not mentioned in the paper) considered in this paper had been specified according to the maximum value compatible with the developed FEM Model, this value had been resulted after a trial and error procedure and was then set to be of $60 \%$ of the plate thickness as a worst case. When applying axial load only to the panel, it had been found that the presence of imperfections resulted in an axial load carrying capacity equal to $94 \%$ of the input axial load.

\section{ANALYSIS AND DISCUSSION OF RESULTS}

The aim is to study the effect of combined load on aluminum stiffened panel by applying different values of lateral pressure on a modeled panel. The model had been calibrated with the same boundary conditions and an axial load of $800 \mathrm{kN}$. Different values of lateral load applied in Z-direction are $800 \mathrm{kN}, 1200 \mathrm{kN}$ and $1600 \mathrm{kN}$ respectively.

The effect of aspect ratio [L/B] and the effect of stiffener cross-section [column slenderness ratio] are also studied. Table 2 illustrates the principal characteristics of the five models used.

Table 2: The Principal Characteristic of the Models

\begin{tabular}{|c|c|c|c|c|c|}
\hline $\begin{array}{l}\text { Principal }>\text { Models } \\
\text { Characteristics }\end{array}$ & Model A & Model B & Model C & ModelD & Model F \\
\hline Length L & $1200 \mathrm{~mm}$ & $1500 \mathrm{~mm}$ & $2000 \mathrm{~mm}$ & $1200 \mathrm{~mm}$ & $1200 \mathrm{~mm}$ \\
\hline Breadth $B$ & $1000 \mathrm{~mm}$ & $1000 \mathrm{~mm}$ & $1000 \mathrm{~mm}$ & $1000 \mathrm{~mm}$ & $1000 \mathrm{~mm}$ \\
\hline Thickness $t$ & $5 \mathrm{~mm}$ & $5 \mathrm{~mm}$ & $5 \mathrm{~mm}$ & $5 \mathrm{~mm}$ & $5 \mathrm{~mm}$ \\
\hline Aspect ratio $\quad \mathrm{L} / \mathrm{B}$ & 1.2 & 1.5 & 2 & 1.2 & 1.2 \\
\hline Flange breadth $\quad B_{f}$ & $40 \mathrm{~mm}$ & $40 \mathrm{~mm}$ & $40 \mathrm{~mm}$ & $50 \mathrm{~mm}$ & $38 \mathrm{~mm}$ \\
\hline Flange thickness $T_{f}$ & $6.7 \mathrm{~mm}$ & $6.7 \mathrm{~mm}$ & $6.7 \mathrm{~mm}$ & $6.7 \mathrm{~mm}$ & $5 \mathrm{~mm}$ \\
\hline Web height & $55.7 \mathrm{~mm}$ & $55.7 \mathrm{~mm}$ & $55.7 \mathrm{~mm}$ & $45 \mathrm{~mm}$ & $65 \mathrm{~mm}$ \\
\hline Web thickness Ts & $3.7 \mathrm{~mm}$ & $3.7 \mathrm{~mm}$ & $3.7 \mathrm{~mm}$ & $5 \mathrm{~mm}$ & $4.7 \mathrm{~mm}$ \\
\hline Column slendemess ratio $\lambda$ & 0.84255 & 0.84255 & 0.84255 & 1.037 & 0.7979 \\
\hline
\end{tabular}

\subsection{Effect of Combined Load}

An illustration of the combined load on a stiffened aluminum panels may be that a bottom panel subjected to compressive axial load due to longitudinal bending moment (hogging) and lateral hydrostatic pressure. Another example may be a bulkhead panel subjected to axial compression (vertically) and hydrostatic pressure from adjacent fluid.

The model used in the calibration presented in chapter 4 and illustrated in figure 1 [model A] with same the boundary conditions and an axial load $800 \mathrm{kN}$ previously with an additional lateral pressure applied in Z-direction as shown in figure 5.

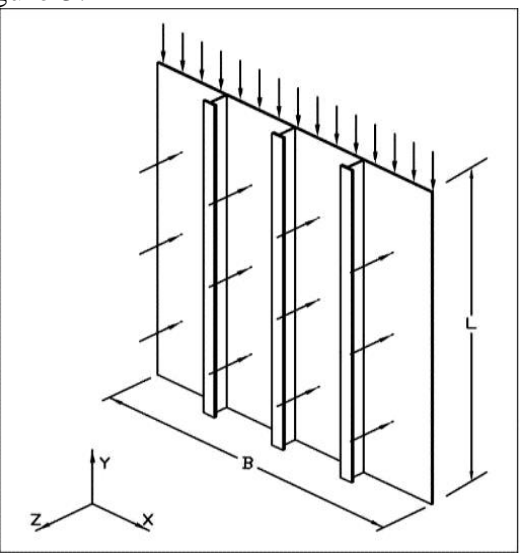

Fig 5: Combined Load on the Stiffened Aluminum Panels

Different values of lateral pressure are exerted on model A in a systematic manner to simulate the possible pressure on stiffened aluminum panels. The obtained results for the displacement versus the axial load carrying capacity are shown in figure $[6,7,8]$. The output of model A taking into account the initial imperfections as mentioned are also plotted in the curves.

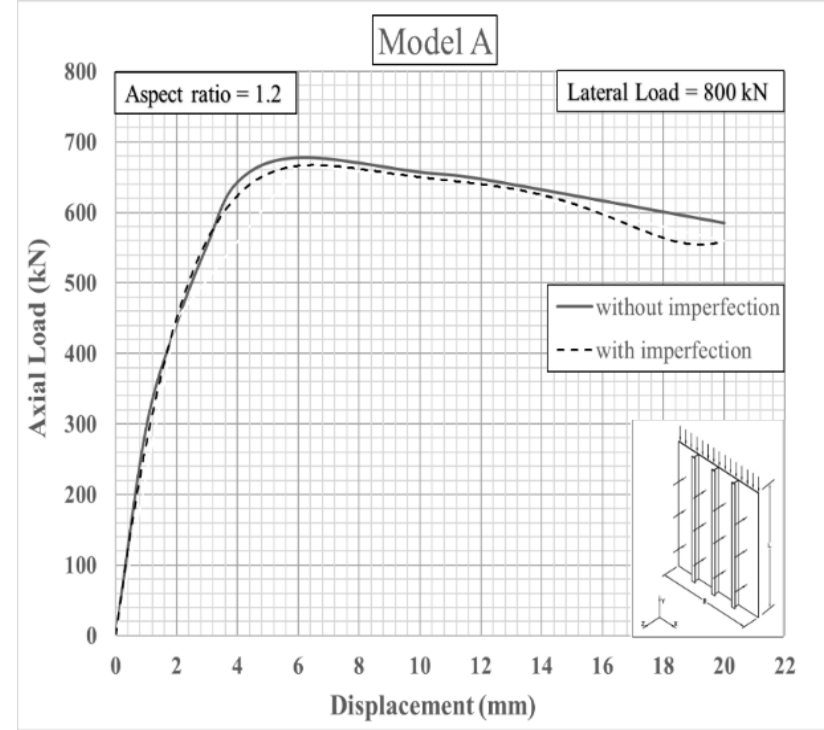

Fig 6: Axial Load vs. Displacement for Lateral Load $800 \mathrm{kN}$ [aspect ratio 1.2] 


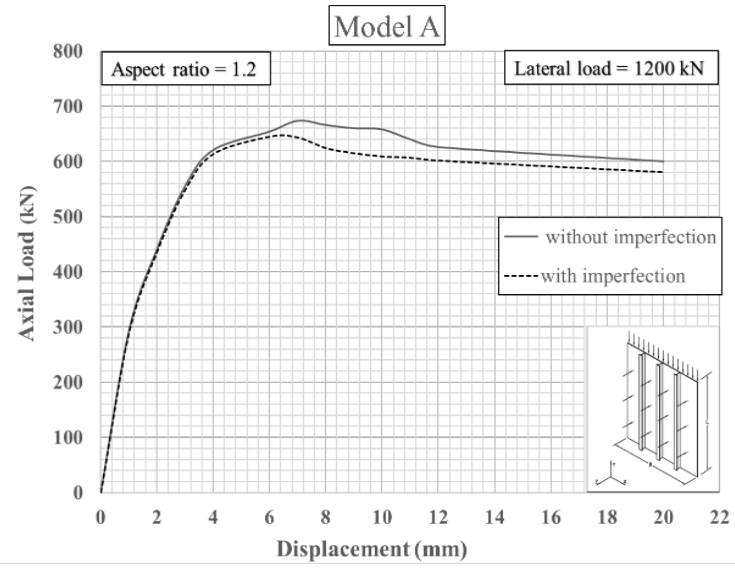

Fig 7: Axial Load vs. Displacement for Lateral Load $1200 \mathrm{kN}$ [aspect ratio 1.2]

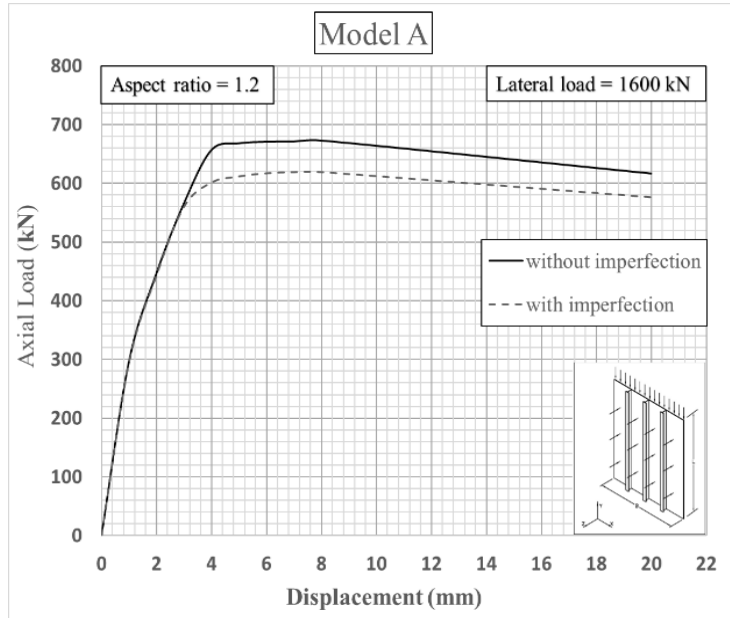

Fig 8: Axial Load vs. Displacement for Lateral Load $1600 \mathrm{kN}$ [aspect ratio 1.2]

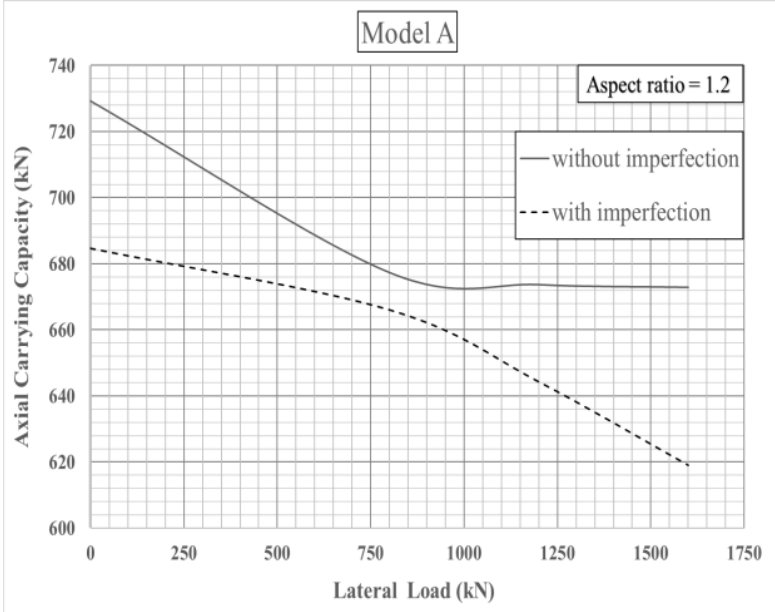

Fig 9: Axial carrying capacity vs. Lateral Load [aspect ratio 1.2]

The maximum axial load carrying capacity for different values of applied lateral load is plotted in figure 9. The trend of the curve in presence of imperfection is completely different than the case without imperfection. It is obvious that the presence of imperfection decreases the carrying capacity. However, case of perfection, the axial carrying capacity remains unchanged with any increase in lateral pressure; this is actually an ideal unrealistic condition.

In case of imperfection the axial carrying capacity of the panel is very sensitive to the application of lateral load beyond $940 \mathrm{kN}$ the carrying capacity drops as the lateral load increases.

The curves plotted in figure 9 may be represented by the following Regression formulae:

-Without imperfections

$$
\mathrm{P}_{\text {axial }}=3 * 10-5\left(\mathrm{P}_{\text {lateral }}\right)^{2}-0.1\left(\mathrm{P}_{\text {lateral }}\right)+728.9
$$

-With imperfections

$$
\mathrm{P}_{\text {axial }}=-2 * 10-5\left(\mathrm{P}_{\text {lateral }}\right)^{2}-0.01\left(\mathrm{P}_{\text {lateral }}\right)+684.8
$$

Where:

$\mathrm{P}_{\mathrm{axial}}=$ Axial Carrying Capacity, $\mathrm{kN}$

$\mathrm{P}_{\text {lateral }}=$ Lateral Load, $\mathrm{kN}$

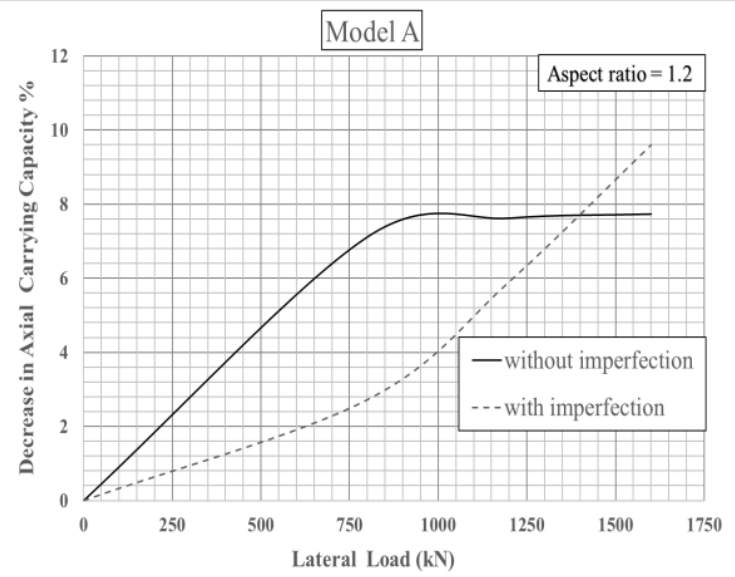

\section{Fig 10: Decrease in Axial Carrying Capacity Percentage vs. Lateral Load}

This is also illustrated in figure 10 which shows that with the presence of imperfection the loss in the axial carrying capacity increases remarkably as the lateral load increases.

\subsection{Effect of Aspect Ratio}

The effect of aspect ratio [L/B] on the strength of the stiffened aluminum panel using two different values [1.5, 2] in addition to the original aspect ratio of model A [1.2] is studied. Different values of lateral loading condition [800, $1200,1600] \mathrm{kN}$ combined with a constant axial load [800 $\mathrm{kN}]$ in all cases are exerted on each three model [A, B, C].

The aspect ratios are selected to be within the range seen in marine applications. For instance, an aluminum mooring boat with principal dimensions [L.O.A $=10.10 \mathrm{~m}$, length P.B.P $=9.55 \mathrm{~m}$, breadth $=2.95 \mathrm{~m}$, depth $=1.67 \mathrm{~m}$ and draft $=0.98 \mathrm{~m}$ ], for a watertight bulkhead shown in figure 11 the aspect ratio is 1.26 less than the maximum value investigated in this study. 


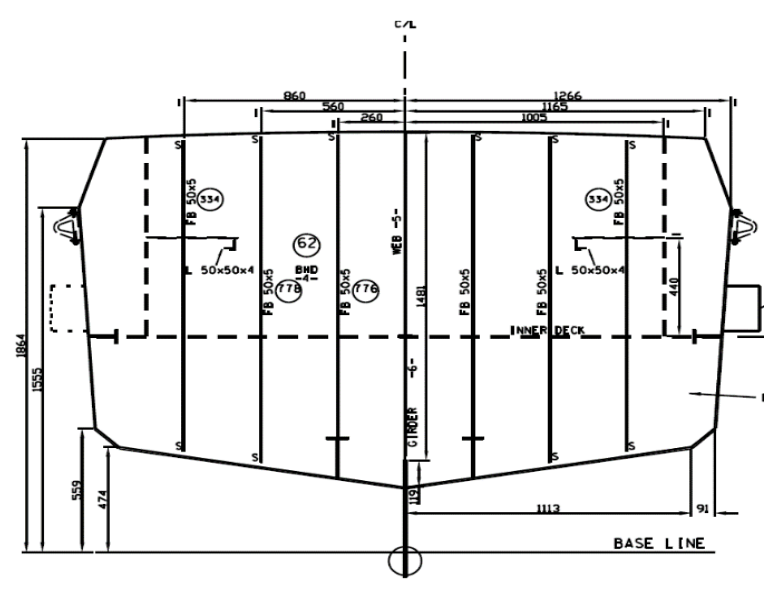

Fig 11: Watertight Bulkhead

\subsubsection{Aspect Ratio 1.2}

This is the aspect ratio of Model A that used to study the effect of combined load. The obtained results for the displacement versus the axial load carrying capacity had been illustrated in figures 6,7 and 8 .

\subsubsection{Aspect Ratio 1.5}

Different values of lateral loading condition $[800,1200,1600] \mathrm{kN}$ with the constant axial load $800 \mathrm{kN}$ on model B with the principal characteristic shown in table 2 are studied. The output of model B including the initial imperfections and without imperfections is plotted in figures 12,13 and 14 .

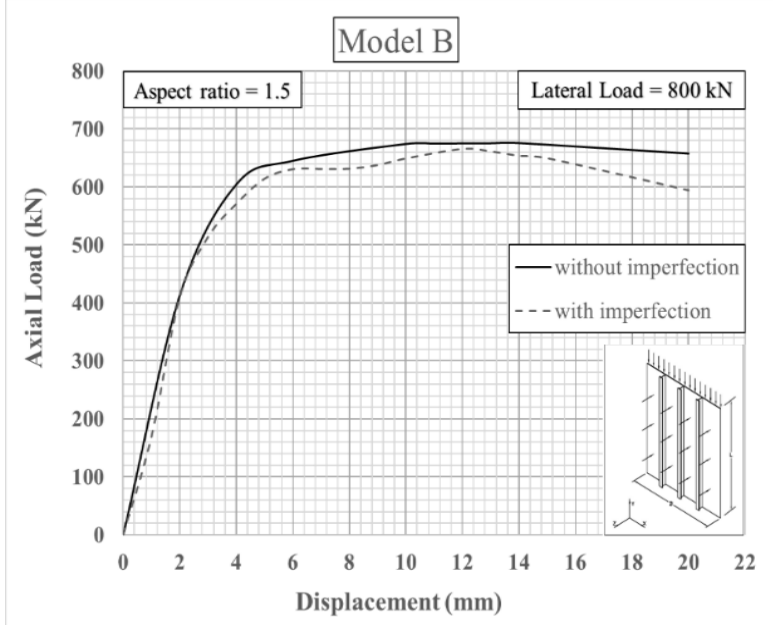

Fig 12: Axial Load vs. Displacement for Lateral Load 800 kN [Aspect Ratio 1.5]

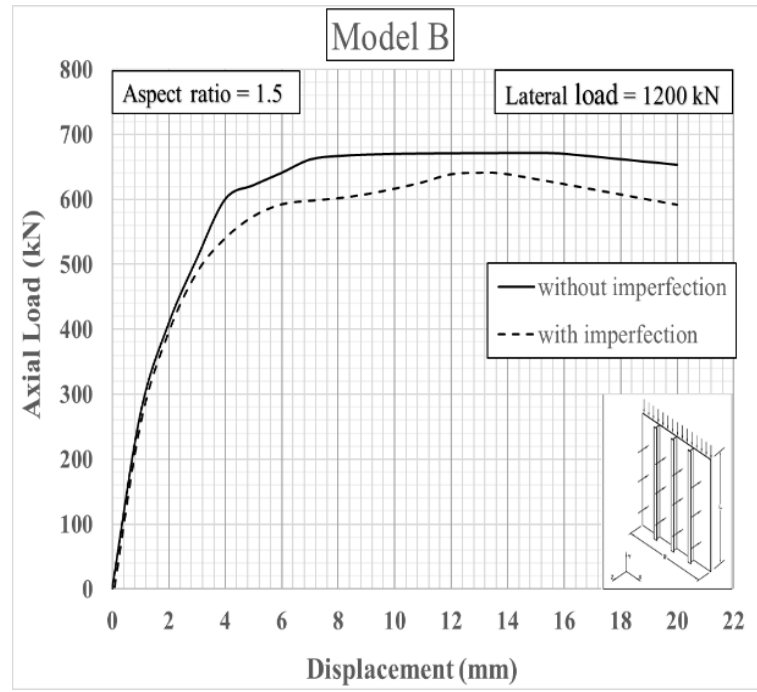

Fig 13: Axial Load vs. Displacement for Lateral Load 1200 kN [Aspect Ratio 1.5]

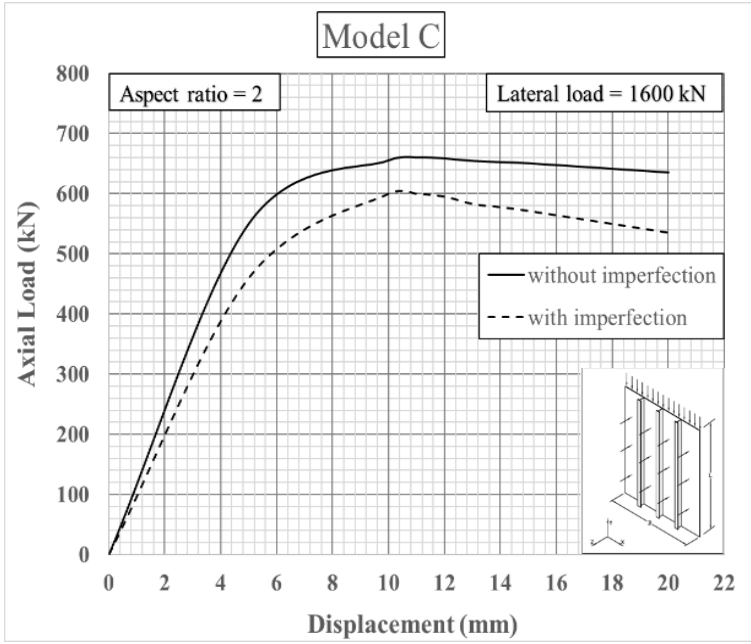

Fig 14: Axial Load vs. Displacement for Lateral Load 5.2.3 Aspect Ratio 2 1600 kN [Aspect Ratio 1.5]

The model $\mathrm{C}$ reported in table 2 is also subjected to the three loading conditions, lateral load [800, 1200, 1600] kN with an axial load of $800 \mathrm{kN}$. The results for axial load versus displacement is plotted in figures 15,16 and 17, taking into account the influence of plate imperfections and the ideal condition (without imperfections). 


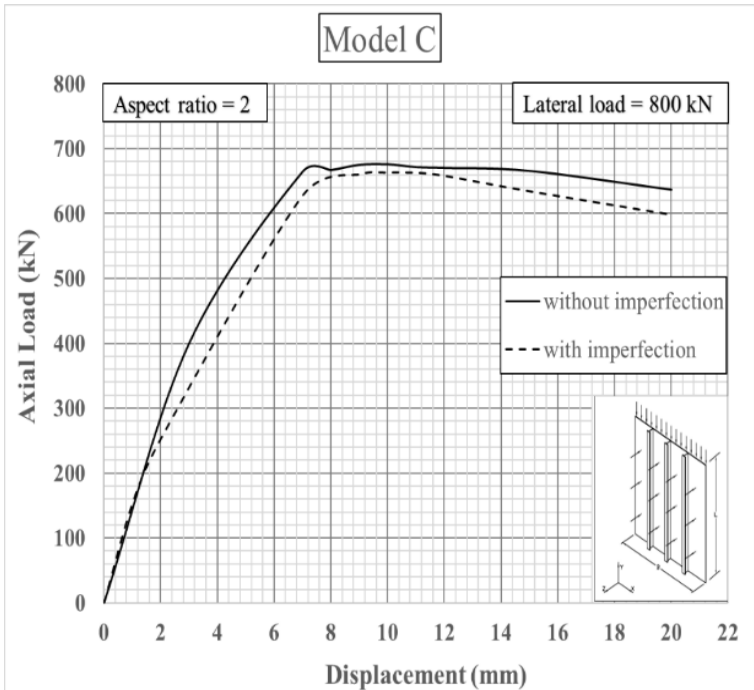

Fig 15: Axial Load vs. Displacement for Lateral Load 800 kN [Aspect Ratio 2]

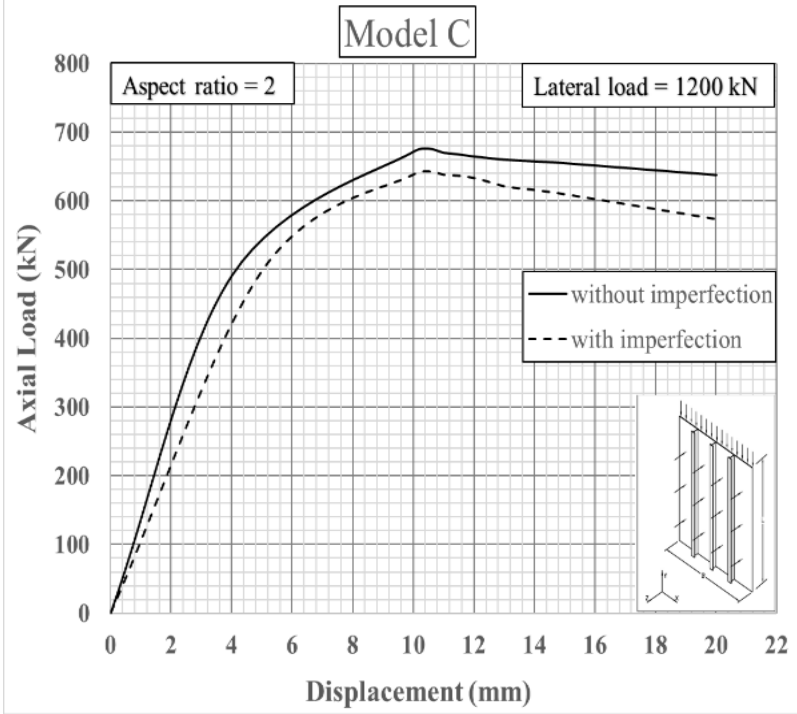

Fig 16: Axial Load vs. Displacement for Lateral Load 1200 kN [Aspect Ratio 2]

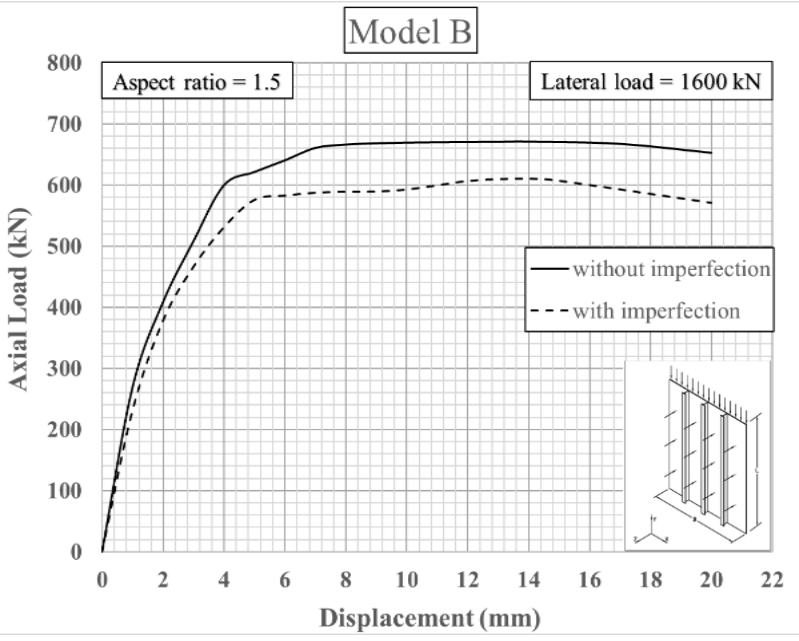

Fig 17: Axial Load vs. Displacement for Lateral Load 1600 kN [Aspect Ratio 2]

\section{Summary curves}

The axial carrying capacity for different values of aspect ratios versus the lateral loads is plotted in figure 18. It is observed that in case of the presence of imperfection, with increase in the aspect ratio, the axial carrying capacity decrease and with increase of lateral load above $940 \mathrm{kN}$ the panel was sensitive to any increase to lateral load or aspect ratio also.

In the absent of imperfections, the effect of increase in aspect ratio on the plate is the decrease in the axial carrying capacity to the value of $940 \mathrm{kN}$ lateral load, the situation of the plate is better than the case of imperfection.

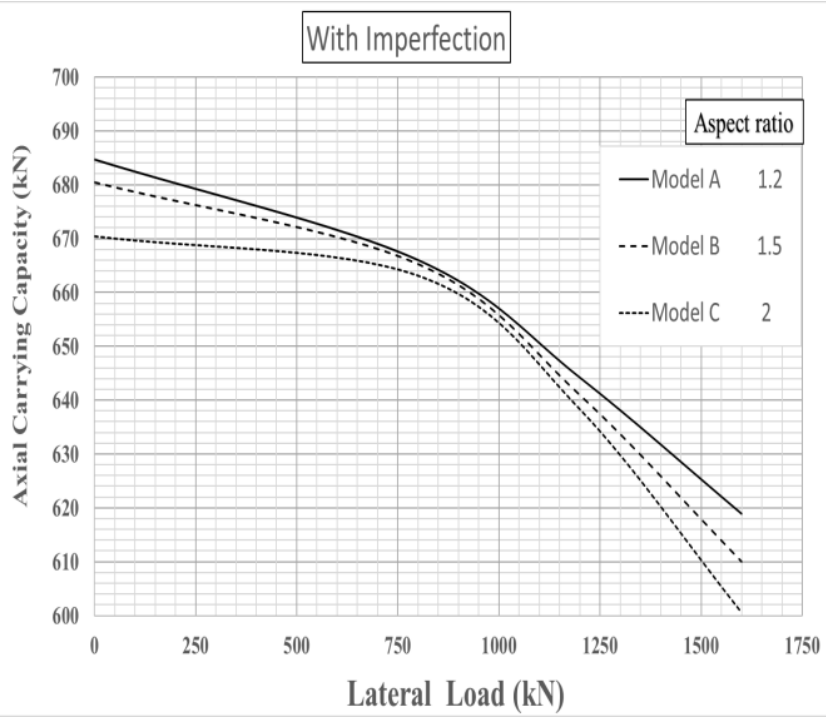

Fig 18: Axial carrying capacity vs. Lateral Load, With Imperfection [Aspect Ratio] 


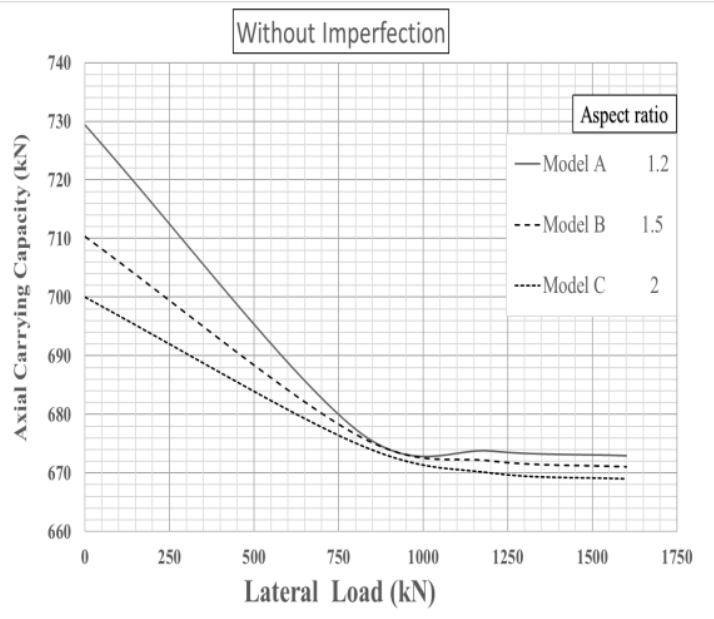

Fig 19: Axial carrying capacity vs. Lateral Load, Without Imperfection [Aspect Ratio]

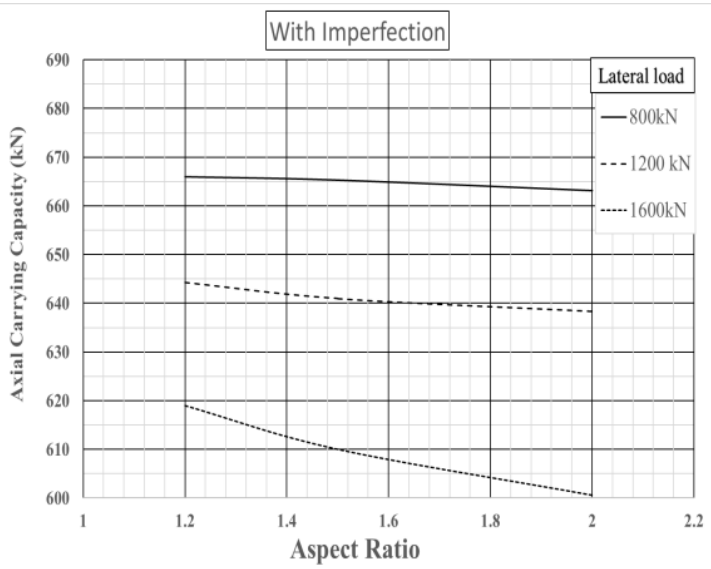

Fig 20: Axial carrying capacity vs. Aspect Ratio [With Imperfection]

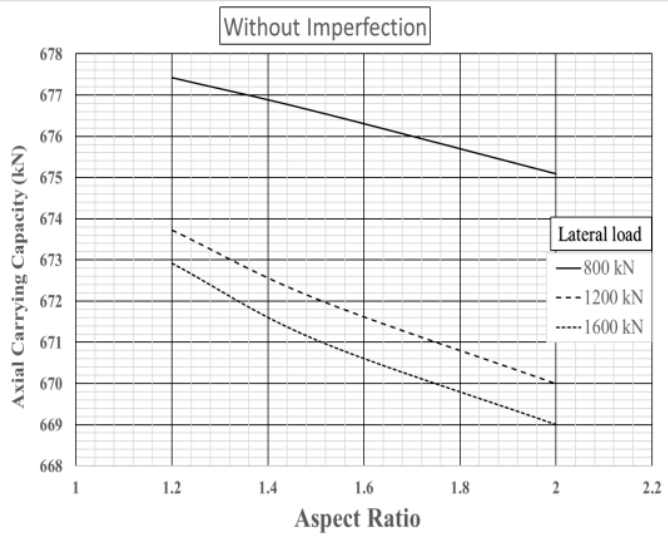

Fig 21: Axial Carrying Capacity vs. Aspect Ratio [Without Imperfection]

The curves plotted in figure 20 and 21 may be practically represented by Regression formulae.

For example,

1- In case of axial load $800 \mathrm{kN}$ combined $800 \mathrm{kN}$ lateral load the formulae are:
-Without imperfections

$$
P_{\text {axial }}=0.36\left(A_{S}\right)^{2}-1.77\left(A_{S}\right)+680.1
$$

-With imperfections

$$
\mathrm{P}_{\text {axial }}=2.54\left(\mathrm{~A}_{\mathrm{S}}\right)^{2}-4.5\left(\mathrm{~A}_{\mathrm{S}}\right)+664.3
$$

2- In case of axial load $800 \mathrm{kN}$ combined $1200 \mathrm{kN}$ lateral load the formulae are:

-Without imperfections

$$
\mathrm{P}_{\text {axial }}=1.8\left(\mathrm{~A}_{\mathrm{S}}\right)^{2}-10.3\left(\mathrm{~A}_{\mathrm{S}}\right)+683.5
$$

-With imperfections

$$
\mathrm{P}_{\text {axial }}=6.9\left(\mathrm{~A}_{\mathrm{S}}\right)^{2}-29.6\left(\mathrm{~A}_{\mathrm{S}}\right)+669.8
$$

3- In case of axial load $800 \mathrm{kN}$ combined $1600 \mathrm{kN}$ lateral load the formulae are:

-Without imperfections

$$
P_{\text {axial }}=2.6\left(A_{S}\right)^{2}-13.2\left(A_{S}\right)+685.1
$$

-With imperfections

$$
P_{\text {axial }}=13.8\left(A_{S}\right)^{2}-67.1\left(A_{S}\right)+679.6
$$

Where:

$\mathrm{P}_{\text {axial }}=$ Axial Carrying Capacity

$\mathrm{A}_{\mathrm{S}}=$ Aspect Ratio

\subsubsection{Effect of Column Slenderness Ratio}

The column slenderness ratio is the ratio of the effective length of a column to the least radius of gyration of its cross section. The column slenderness ratio is representing the stiffener cross section properties.

Three values of column slenderness ratio are exerted on model $\mathrm{A}$, model $\mathrm{D}$ and model $\mathrm{F}$ as illustrated in table 3. Applying different values of lateral pressure $[800,1200,1600] \mathrm{kN}$ with axial load $800 \mathrm{kN}$ on the models in a systematic manner to simulate various values of column slenderness ratio on the strength of stiffened aluminum panels. The obtained results for the axial carrying capacity versus lateral load taken into account initial imperfections are shown in figure 21 and 22.

Table 3: Values of Column Slenderness Ratio

\begin{tabular}{|l|c|c|c|c|c|}
\hline \multicolumn{3}{|c|}{ Plate Dimensions } & \multicolumn{4}{|c|}{ Stiffener Dimensions } \\
\cline { 3 - 7 } & & Items & Model A & Model D & Model F \\
\hline Length L & $1200 \mathrm{~mm}$ & Flange breadth $b_{f}$ & $40 \mathrm{~mm}$ & $50 \mathrm{~mm}$ & $38 \mathrm{~mm}$ \\
\hline Breadth B & $1000 \mathrm{~mm}$ & Flange thickness $t_{f}$ & $6.7 \mathrm{~mm}$ & $6.7 \mathrm{~mm}$ & $5 \mathrm{~mm}$ \\
\hline Thickness $\quad \mathrm{t}$ & $5 \mathrm{~mm}$ & Web height hw & $55.7 \mathrm{~mm}$ & $45 \mathrm{~mm}$ & $65 \mathrm{~mm}$ \\
\hline Effective Breadth & $250 \mathrm{~mm}$ & Web thickness $t_{w}$ & $3.7 \mathrm{~mm}$ & $5 \mathrm{~mm}$ & $4.7 \mathrm{~mm}$ \\
\hline Plate Slenderness Ratio $\beta$ & 10.93 & $\begin{array}{c}\text { Column slenderness } \\
\text { ratio } \lambda\end{array}$ & 0.84255 & 1.037 & 0.7979 \\
\hline
\end{tabular}

In case of imperfections the decrease of column slenderness value makes the carrying capacity increase as shown in Figure 22.

In the absence of imperfections, the axial carrying capacity is highly sensitive to any increase in slenderness ratio, but is less sensitive to the increase in lateral load as shown in Figure 23. 


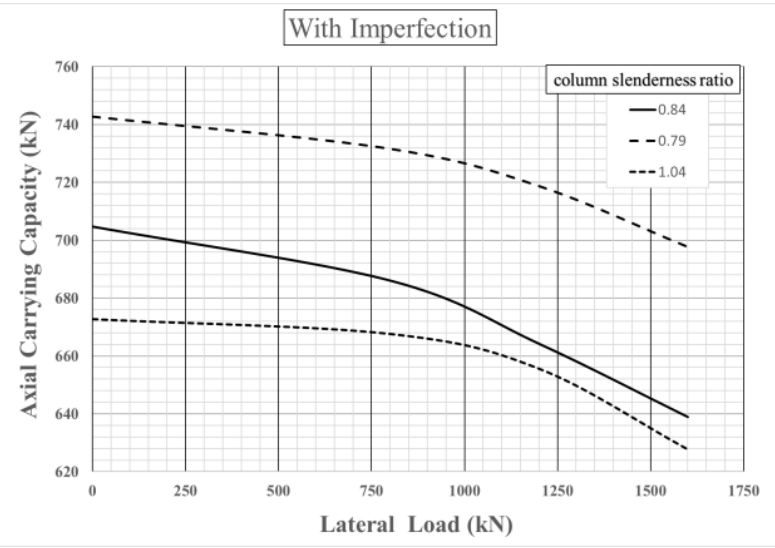

Fig 22: Axial carrying capacity vs. Lateral Load, With Imperfection [Column Slenderness Ratio]

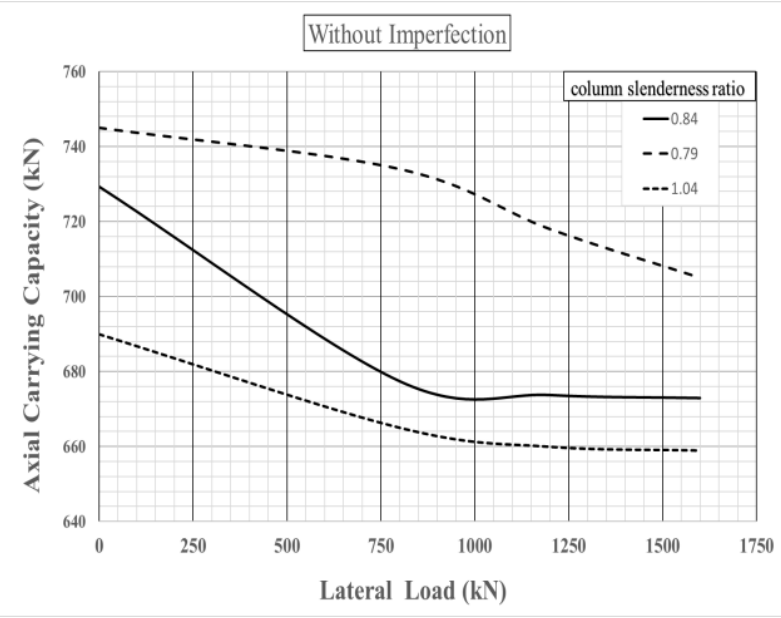

Fig 23: Axial Carrying Capacity vs. Lateral Load, Without Imperfection [Column Slenderness Ratio]

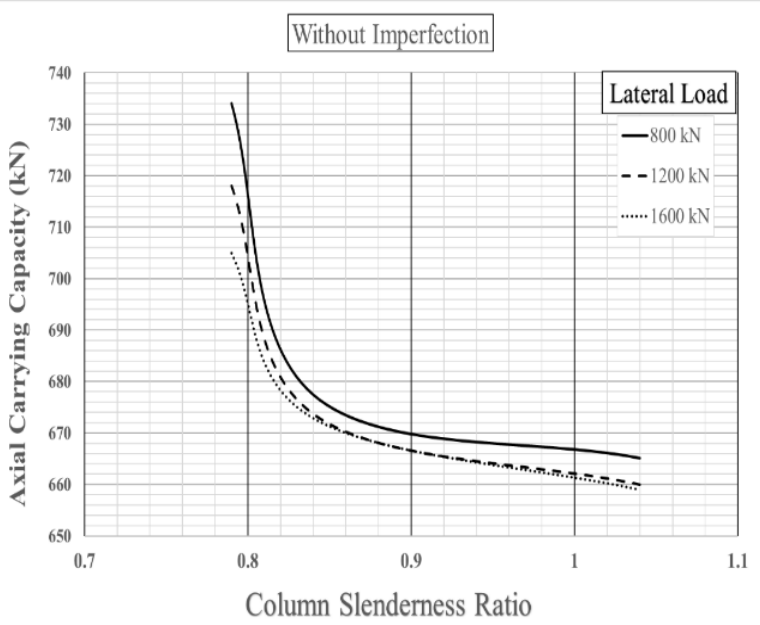

Fig 24: Axial Carrying Capacity vs. Column Slenderness Ratio [Without Imperfections]

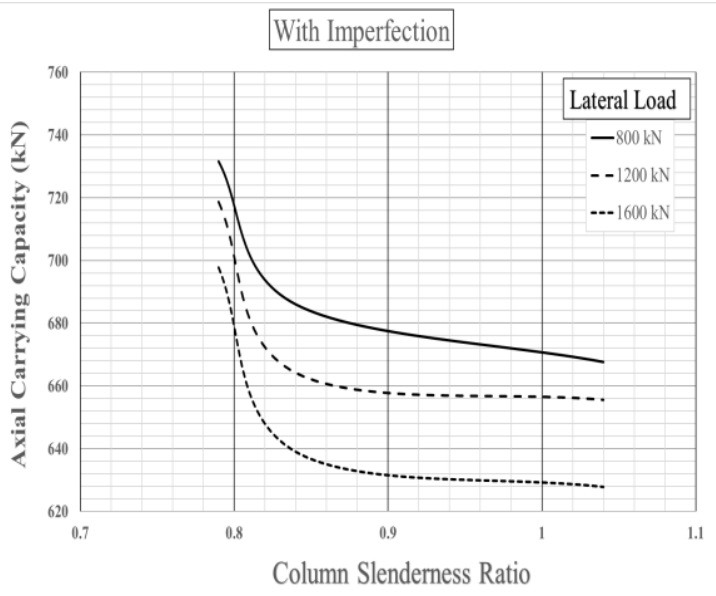

Fig 25: Axial Carrying Capacity vs. Column Slenderness Ratio [With Imperfections]

The curves plotted in figure 24 and 25 may be practically represented by Regression formulae.

For example,

1- In case of axial load $800 \mathrm{kN}$ combined $800 \mathrm{kN}$ lateral load the formulae are:

-Without imperfections

$$
\mathrm{P}_{\text {axial }}=4279.8(\lambda)^{2}-8107.7(\lambda)+4468
$$

-With imperfections

$$
P_{\text {axial }}=3277(\lambda)^{2}-6252.9(\lambda)+3626.2
$$

2- In case of axial load $800 \mathrm{kN}$ combined $1200 \mathrm{kN}$ lateral load the formulae are:

-Without imperfections

$$
\mathrm{P}_{\text {axial }}=3268(\lambda)^{2}-6212.4(\lambda)+3586.3
$$

-With imperfections

$$
P_{\text {axial }}=4186.4(\lambda)^{2}-7913.6(\lambda)+4357.8
$$

3- In case of axial load $800 \mathrm{kN}$ combined $1600 \mathrm{kN}$ lateral load the formulae are:

-Without imperfections

$$
\mathrm{P}_{\mathrm{axial}}=2288(\lambda)^{2}-4371(\lambda)+2730.2
$$

-With imperfections

$$
\mathrm{P}_{\mathrm{axial}}=4476(\lambda)^{2}-8471.1(\lambda)+4596.4
$$

Where:

$\mathrm{P}_{\mathrm{axial}}=$ Axial Carrying Capacity

$\lambda=$ Colum Slenderness Ratio

\section{Conclusions}

1. The developed FE Model is a powerful tool to investigate the structural behavior of aluminum panels subject to combined loading.

2- The effect of increasing lateral load without imperfections and with imperfections had been investigated and regression formulae had been derived. In the absence of imperfections, the load carrying capacity is slightly affected by any increase in lateral load; the decrease in 
load carrying capacity is found to be between 7.1 to $7.7 \%$ of the value obtained when applying the axial load only.

In the presence of imperfections, any increase in lateral load had resulted in a remarked decrease in the axial load carrying capacity. The effect of imperfections had resulted in an average decrease about 9\% in the load carrying capacity in case of an applied lateral load 1600 $\mathrm{kN}$.

3- Any slight an increase in aspect ratio affects the ability of the panel withstand any increase in load and deformation especially in case of imperfections.

When applying axial load only an increase in aspect ratio of $25 \%$ resulted in a decrease in the axial carrying capacity by about $0.6 \%$ in case of imperfections; and in the of absence of imperfections the axial carrying capacity decreased about $2.6 \%$.

In case of combined load, a $25 \%$ increase in aspect ratio made the carrying capacity decrease with $0.1 \%$ with imperfections and $0.12 \%$ without imperfections.

The effect of imperfections with increase aspect ratio made the carrying capacity decrease between $6.1 \%$ to $8.1 \%$.

4- The decrease in column slenderness ratio improves the axial carrying capacity of the plate.

When applying axial load only an increase in column slenderness ratio of about $25 \%$, decreased the axial carrying capacity about $4.5 \%$ in case of presence imperfections; without imperfections, the axial carrying capacity decreased about 5.3\%.

In case of combined load, an increase in column slenderness ratio of $25 \%$ made the carrying capacity decrease by $2.6 \%$ with imperfections; without imperfections this ratio is $1.8 \%$.

The effect of imperfections with increase in column slenderness ratio made the carrying capacity decrease between $4.5 \%$ to $10.9 \%$.

5- It is noted that the axial carrying capacity of panel is more sensitive to the change of column slenderness ratio than that of the aspect ratio with the same increase rate.

\section{References}

[1] Michael Skillingberg, "Aluminium and the Sea", Marine Log, 2007.

[2] Richmond Pearson Hobson, "Notes on the yacht Defender and the use of aluminum in marine construction", Assistant Naval Constructor, US Naval Institute, 1897.

[3] The Aluminum World, "Aluminum: its alloys and their use in ship construction", Volume 2, No. 3, December 1895.

[4] Matthew CoRette, "Strength and Reliability of Aluminium Stiffened Panels", June 2005.

[5] Xiaozhi Wang, Akira Akiyama, "Buckling and Ultimate Strength of Aluminum Plates and Stiffened Panels in Marine Structures",2005.
[6] Jeom Kee Paik, Celine Andrieu, and H. Paul Cojeen. "Mechanical Collapse Testing on Aluminum Stiffened Plate Structures for Marine Applications", American Bureau of Shipping. 2007.

[7] Mohammad Reza Khedmati, Mohammad Reza Zareei, "Sensitivity Analysis on the Elastic Buckling and Ultimate Strength of Continuous Stiffened Aluminium Plates Under Combined Inplane Compression and Lateral Pressure", 26 May 2009.

[8] Mohammad Reza Khedmati, Masoud Pedrama, "The effects of geometrical imperfections on the ultimate strength of aluminium stiffened plates subject to combined uniaxial compression and lateral pressure", Ships and Offshore Structures, 2012.

[9] Teresa Magoga, Craig Flockhart, "Effect of weld-induced imperfections on the ultimate strength of an aluminium patrol boat determined by the ISFEM rapid assessment method", Jan 2013.

[10] Mohammad Reza Khedmati, Hamid Reza Memarian, Manouchehr Fadavie, Mohammad Reza Zareei, "Ultimate Strength of Continuous Stiffened Aluminium Plates Under Combined Biaxial Compression and Lateral Pressure", Latin American Journal of Solids and Structures, 2015.

[11] Chenfeng Li, Huilong Ren, Zhiyao Zhu, C. Guedes Soares, "Numerical investigation on the ultimate strength of aluminium integrally stiffened panels subjected to uniaxial compressive load", Thin-Walled Structures, 2018.

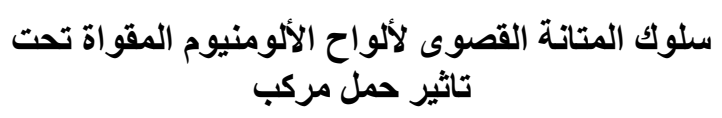

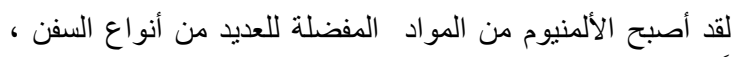

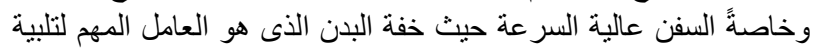

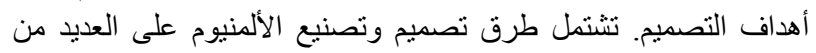

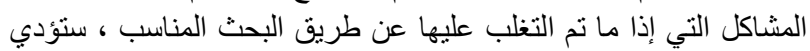

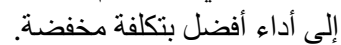

يدرس هذا البحث المنانة القصوى لألو اح الألومنيوم المقواة تحت تاثنير

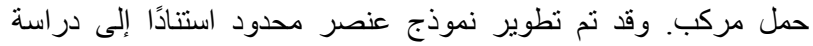

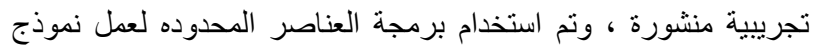
يضاهى نموذج تم عمل عليه تجارب معملية وقد تحققنا من صحة الندة النتائج.

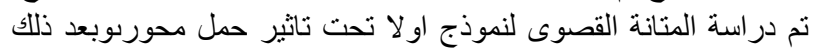

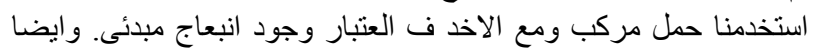

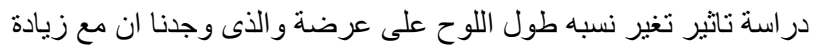

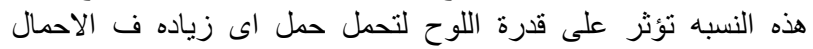

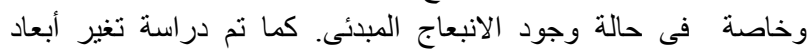
التقويات المثبتة على اللوح و تاثير ذللك على منانة اللوح و وعمل علاقات التات بين

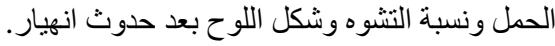

